\title{
Eine Botschaft für den Bundestagswahlkampf
}

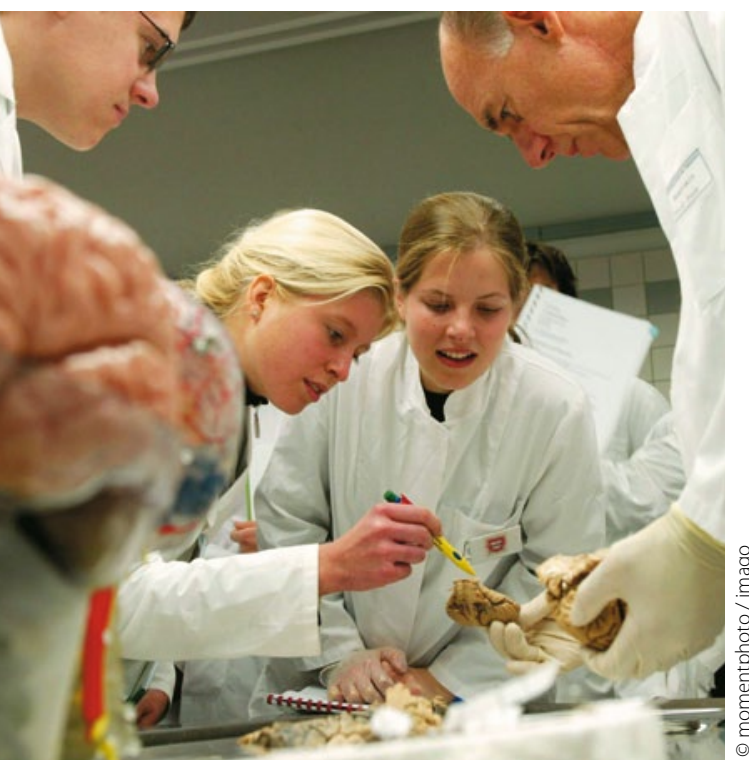

Die universitäre Ärzteausbildung hinkt der Versorgungsrealität hinterher. Das soll sich mithilfe des KV-Systems ändern.

\section{Den Sicherstellungsauftrag stärken und ein "Versorgungsdesaster" ver- meiden: Die Vertreterversammlung der Kassenärztlichen Bundesvereini- gung setzt sich hohe Ziele.}

— Im kommenden Bundestagswahlkampf wollen Ärzte mit einer einheitlichen Stimme auftreten. Die Vertreterversammlung der Kassenärztlichen Bundesvereinigung (KBV) hat sich daher auf ein gemeinsames Positionspapier verständigt. Darin gibt es drei Kernbotschaften:

(1) Der Sicherstellungsauftrag soll gestärkt,

2 die Prävention verbessert sowie

3 die ärztliche Aus- und Weiterbildung an Versorgungsnotwendigkeiten angepasst werden.

Unter anderem sollte es eine klare Wettbewerbsordnung für das Verhältnis von Kollektiv- und Selektivverträgen geben, sagte KBV-Chef Dr. Andreas Köhler. Selektivverträge müssten so beschaffen sein, dass sie ein hohes Versorgungsniveau unter bürokratiearmen Bedingungen sicherstellen. Die Vergütung derteilnehmenden Ärzte müsse mindestens dem Umfang der kollektiv-vertraglichen Vergütung entsprechen.

Die Versorgungsverbesserungen sollte allen GKV-Versicherten zugutekommen und deshalb in den Kollektivvertrag übernommen werden, betonte Köhler.

\section{Eigenverantwortung gemäß Versichertenwahltarif}

Um den Zugang zur ambulanten Versorgung langfristig zu sichern, müsse es Steuerungsinstrumente geben, forderte der KBV-Chef. Er schlug Wahltarife mit Kostenerstattung als ein solches Instrument vor. Die GKV-Versicherten sollten zwischen drei Tarifen wählen können. Damit könnten sich die Versicherten entscheiden, welchen Grad der Eigenverantwortung sie bei der Versorgung übernehmen wollen.

KBV-Vorstand Regina Feldmann kritisierte, dass die universitäre Ausbildung zukünftiger Ärzte nicht mehr der Versorgungsrealität entspreche. Das KVSystem müsse sich dort umgehend einschalten, andernfalls drohe ein „Versorgungsdesaster“. Freiberufliche Ärzte und ebenso Psychotherapeuten müssten außerdem als Präventionslotsen gestärkt werden.

Das Positionspapier lag bis zum Redaktionsschluss noch nicht vor. Inhaltliche Ergänzungen aus der Vertreterversammlung müssten zunächst noch im Vorstand abgestimmt werden, so KBVSprecher Roland Stahl.

SUNNA GIESEKE *

\section{TV-Kampagne}

\section{Für ein besseres Image der Ärzteschaft}

Die KBV startete im Frühjahr eine groß angelegte Imagekampagne „Wir arbeiten für Ihr Leben gern." Damit soll das Image von Ärzten und Psychotherapeuten aufpoliert werden. Die Aktion sei auf fünf Jahre auslegt und werde insgesamt 15 Millionen $€$ kosten, so KBV-Sprecher Roland Stahl. Ein Großteil der Gesamtsumme werde bereits 2013 investiert. Ende April ist der erste Spot kurz vor der Tagesschau in der ARD gelaufen. Es sei zudem geplant, Werbefilme auch im Kino zu zeigen. Darüber hinaus sollen die Botschaften bundesweit plakatiert werden, so Stahl.

Ziel der Kampagne sei, ein realistisches Bild der Arbeit der Ärzte in die Öffentlichkeit zu transportieren. Daher habe man für die Filmaufnahmen und die Fotoshootings „echte“ niedergelassene Ärzte und Psychotherapeuten gesucht. Die Werbekampagne sei aufgrund anhaltender Angriffe auf Ärzte wie zum Beispiel bei der Korruptionsdebatte entwickelt worden. Dennoch sei es keine Protestaktion, so Stahl. „Aber wir wollen auch nichts beschönigen." Die Tätigkeit der Ärzte und Psychotherapeuten sei unersetzlich, dafür verdienten sie Anerkennung. Darüber hinaus wolle man die Attraktivität des Arztberufes steigern.

Auch die Deutsche Krankenhausgesellschaft hatte kürzlich eine Imagekampagne gestartet.Sie soll drei Jahre laufen. Die Kosten dafür betragen 3 Millionen $€$.

SUNNA GIESEKE - 